\title{
Evaluation of information ethical issues among undergraduate students: An exploratory study
}

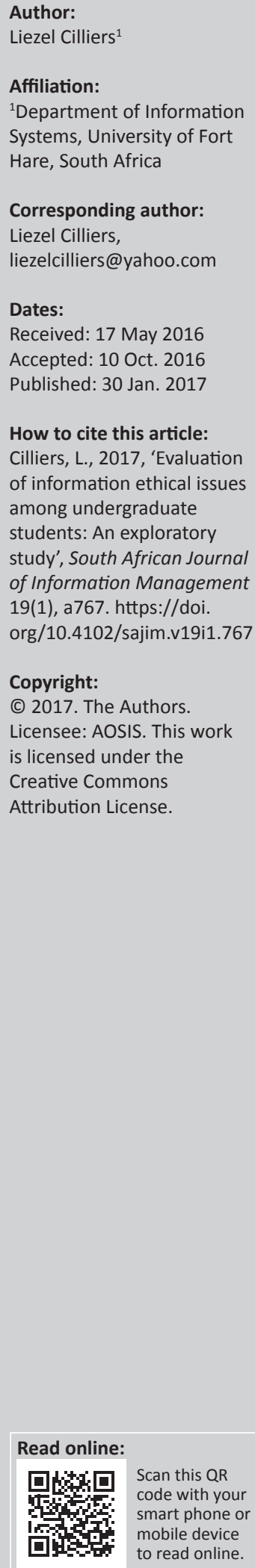

Background: Higher education is increasingly making use of information and communication technology (ICT) to deliver educational services. Young adults at higher educational institutions are also making use of ICTs in their daily lives but are not taught how to do so ethically. Software piracy, plagiarism and cheating, while making use of ICTs, are the most common ethical dilemmas that will face digital natives.

Objective: The purpose of this article was to investigate information ethics of young adults at a higher education institution in the Eastern Cape Province of South Africa.

Method: This study made use of a positive, quantitative survey approach. A closed-ended questionnaire was distributed to a group of 312 first-year students, who had registered for a computer literacy class. A response rate of $69.2 \%$ was recorded, resulting in 216 students participating in the study. The results were analysed using descriptive and inferential ( $t$-tests) statistics in SPSS V22.

Results: The results indicated that plagiarism is a problem among first-year students, and elements of authorship should be included in the curriculum. Students understood what software piracy was but did not think it was wrong to copy software from the Internet. Finally, the students understood that cheating, while making use of technology, is wrong and should be avoided.

Conclusion: The recommendation of the study then is that information ethics must be included in the undergraduate curriculum in order to prepare students to deal with these ethical problems.

\section{Introduction}

Higher education is responsible for the development of student autonomy and thereby the development of a knowledge society (Duarte 2014). In order to achieve these goals, higher education institutions (HEIs) are increasingly making use of information and communication technology (ICT) to deliver services (Alshwaier, Youssef \& Emam 2012; Koch, Assuncao \& Netto 2012). HEIs have become dependent on ICT to manage large amounts of data, improve the delivery of educational material, offer digital content and make classes more interactive (Koch et al. 2012).

In HEI interactive classes, young adults (typically aged between 18 and 24 years) can access information and resources making use of the ICT infrastructure. This generation is considered to comprise 'digital natives' who grew up with ICT, unlike their parents who had to learn to use new ICT services (Prensky 2001). Skiba (2014) reported that 79\% of young adults own smart phones, with $70 \%$ of them using devices to stay connected in class.

This knowledge era does, however, bring about some unique challenges, such as the privacy and confidentiality of technology users as well as the accuracy of, and access to, digital technologies and ownership of such information (Halawi \& McCarthy 2013; Mutula \& Mmakola 2013; Sturges 2009). In order to address authorship, the flip side of plagiarism, the field of information ethics was introduced. Information ethics focuses on the relationship between the creation, organisation, dissemination and use of information, and extends to the ethical standards and moral acts controlling human behaviour around the use of such information by others without appropriate acknowledgement (Capurro 2007). Kim, Kim and Lee (2013) argued that while ethical problems in the ICT field do not differ from broader societal ethical issues, a thorough knowledge of ICT practices is necessary in order to comprehend the root cause of such ethical problems.

The two most common ethical problems faced by students in higher education are plagiarism and software piracy. Plagiarism is defined as 'The deliberate or reckless representation of another's words, thoughts, or ideas as one's own without attribution in connection with submission of 
academic work' (University of North Carolina 2014:1). Software piracy involves the unauthorised copying of software to avoid purchasing cost and can include copying of movies, music, games or software programs (Hsieh \& Lee 2012). Leonard and Cronan (2005) suggested that the Internet makes information and software resources readily available and students, therefore, believe that it is acceptable practice to download movies or music from websites. This attitude then extends to the academic work of the student who plagiarises Internet resources. Alternatively, students can also use technology to cheat when taking tests or examinations. Underwood (2007:218) stated that ICT and Internet skills may provide students with an educational advantage, but there is also: 'recognition by students that the technologies can give them an edge, i.e. they can cheat'.

The purpose of this article is to investigate the information ethics of young adults at an HEI in the Eastern Cape Province of South Africa. While ICT has become acceptable in the higher education landscape, there is poor understanding of ethical issues for the purpose of teaching, learning and research. This is especially true in developing countries where there is also a lack of ethical education, awareness and policy regulation around the issue. Computer Science and Information Systems' lecturers in higher education have previously indicated that information ethics is an area that must be investigated and included in the curriculum in order to improve the social responsibility of young adults (Leonard \& Cronan 2005; Straub \& Collins 1990).

\section{Literature review}

ICT has become essential in teaching and learning at HEIs, where it is used by both staff and students as a learning, research and communication tool (Jamil, Shah \& Tariq 2013b). The purpose of information technology (IT) is to generate knowledge that can be used to solve problems, unlock creativity and increase productivity (Halawi \& McCarthy 2013). IT, therefore, can be defined as a set of tools that help students acquire information and perform tasks related to information processing (Haag \& Keen 1996). Typical tasks that will be performed include accessing resources, completing assessments, preparing for presentations and communicating with peers or lecturers. While performing these tasks, ethical issues around acknowledging sources of information, for instance, will need to be addressed. Information ethics will guide the moral decision-making of young adults while making use of technology whether in the workplace, at school or in society in general (Jamil, Hussain \& Tariq 2013a).

Ethics is considered to be the guidelines influencing human social behaviour intended to protect and fulfil the rights of individuals in a society (Marshall 1999). The definition of information ethics as proposed by Johnson (1985) was adopted for this study. Information ethics refers to a set of rules or principles used for moral decision-making regarding computer technology and computer use. Mason (1986) identified three critical areas that should be protected by information ethics, which include an individual's right to keep information about himself or herself private, the right to ascertain that the data are accurate and maintain ownership of it and an individual's right to have access to information.

Walter Maner first introduced information ethics in the mid1970s. Maner (1995:3) stated that he: 'found it hard to convince anyone that computer ethics was anything other than an oxymoron'. Initially, the discipline only focused on the computing profession, which was responsible for the development of computer systems, but with the advent of the Internet, the emphasis soon moved to the end-users of computer and related technologies as issues such as intellectual property rights, plagiarism, software piracy and privacy had to be considered (Halawi \& McCarthy 2013; Hsieh \& Lee 2012). Two threats mentioned among the issues can be categorised as unethical Internet behaviour and are responsible for serious legal offenses. Freestone and Mitchell (2004) coined the term 'aberrant behaviour', which is used to describe the inappropriate use of the Internet without fear of punishment.

Meanwhile, Halawi and McCarthy (2013) stated that research in the information ethics' field is still inadequate and is mostly driven by two considerations. The first is public awareness about the vulnerability and misuse of information systems. This type of awareness depends on media coverage of specific incidents which helps to raise public awareness through discussions of how to manage these ethical issues in a more socially acceptable manner (Straub \& Collins 1990). The second consideration has been the concerns of information system professionals that found the unacceptable, illegal and unethical use of computers to be problematic (Halawi \& McCarthy 2013).

In order to address these concerns, Mason (1986) created a theoretical social framework to deal with ethical issues of the knowledge age. Mason identified four issues known as 'PAPA', which stand for privacy, accuracy, property and accessibility:

- Privacy deals with the decision about what information to reveal to others, under what conditions and with what safeguards.

- Accuracy refers to the authenticity, fidelity and accuracy of information.

- Property refers to who owns information, how access should be granted to this resource and what are the just and fair prices for its exchange.

- Accessibility guides the individual as to what information a person or an organisation has the right or the privilege to obtain, under what conditions and with what safeguards.

While the PAPA framework has remained popular for the last two decades to address information ethics, Halawi and McCarthy (2013) and Mason (1986) stated that with the advancements made in IT, unethical behaviour will increase. This type of unethical behaviour could include opportunistic behaviour such as hacking, spamming, denial of service attacks, identity theft and unauthorised duplications of 
software or content (Masrom et al. 2010). Young adults should be educated about information ethics so that they develop respect for authorship and ownership and do not indulge in opportunistic behaviour.

Pierce and Henry (1996) proposed that there are three influences that must be considered when an individual is confronted with an ethical decision related to IT or computer use. The first is the personal code of ethics which the individual develops through observation and experience. The second influence is the informal code of ethics, which is seen as acceptable behaviour in the workplace or endorsed by peers, and the third is the formal code of computer ethics which can include the institutional code or policy and legislation.

Among institutions, in particular, HEIs are increasingly concerned that the Internet will motivate students to be dishonest or unethical in their use of information. Unethical behaviour can include plagiarism, software piracy, fraud, falsification and misuse of information (Akbulut et al. 2008). Teston (2008) reported that $48 \%$ of students in the United States believe software piracy is legal. The computer curriculum, therefore, should include information ethics which will raise the awareness of these issues and increase the understanding of the implications of unethical behaviour. This will provide students with the tools to analyse and evaluate ethical dilemmas they may encounter in the field of ICT. However, at present, very few curricula include any information ethics in their list of objectives or values to be inculcated as learning outcomes (Jamil et al. 2013a).

Literature suggests that such values and attitudes have been found to be the most significant factor that will influence an individual's intention to behave ethically or unethically (Ajzen 1991; Leonard \& Cronan 2005). Attitude can be influenced by five environmental factors, including societal belief system, and personal, professional, legal and business factors. The societal environment includes the social, religious and cultural values that impact the individual. Personal values are an individual's personal goals and experiences and are most often influenced by family, peers and significant others. The professional environment consists of the codes of conduct and professional expectations of an individual's profession, while the legal environment captures the law and the legislation of the country. Finally, the business environment consists of a company's stated policies which may increase the probability of ethical behaviour and persuade individuals to refrain from prohibited behaviour (Leonard \& Cronan 2005).

In the business environment, cell phones are used prolifically. Young adults working and studying use them and other technologies; hence, they must be taught about information ethics in order to mitigate some of the effects experienced with plagiarism and software piracy. When young adults are taught the moral codes of handling and disseminating information, it will propagate knowledge about issues of privacy, censorship, copyright, fair use and access to information (Limo 2010). As the young adults' attitude regarding these issues change, it will also contribute to their social conduct and the growth of the knowledge era. This will ultimately lead to a morally informed society (Halawi \& McCarthy 2013).

\section{Methodology}

The study made use of a positivistic, quantitative research approach. The study population consisted of 312 first-year students registered for a computer literacy course. The semester course consisted of students registered for commerce, law and social sciences degrees. The response rate of the students was $69.2 \%$ (216 students). This is considered an adequate response (Oates 2006). The study used the Cronbach's alpha coefficient to determine the reliability of the questionnaire. Cronbach's alpha values of 0.70 and above are typically employed as a rule of thumb to denote a good level of internal reliability, values between 0.50 and 0.69 denote an acceptable level of reliability and values below 0.50 denote poor and unacceptable levels of reliability. The reliability factor for the questionnaire was 0.604 which denotes an acceptable level of reliability (Bryman 2012).

As part of the course material, all the students were asked to complete an online questionnaire that evaluated their knowledge about information ethics. The questionnaire was developed and tested previously by Jamil et al. (2013a). The positivistic, quantitative approach was chosen owing to time constraints and the convenience of students, as it was accessible online. The questionnaire was designed to understand students' perceptions of information ethical behaviour in various activities that they may encounter while studying. The questionnaire consisted of two parts: Part 1 was designed to collect students' demographic information, while Part 2 comprised 14 statements on which respondents were required to respond making use of a Likert scale ( $1=$ strongly disagree to $5=$ strongly agree). The statements were divided into three categories: plagiarism, piracy and cheating. A pilot study was conducted prior to the distribution of the questionnaire in order to test for ambiguity, completeness and user-friendliness.

The questionnaire items were analysed making use of the Statistical Package for Social Sciences (SPSS) Version 22 in order to develop descriptive statistics (frequencies and percentages) and deferential statistics (mean, standard deviations and independent sample t-test at $\alpha=0.05$ ).

\section{Results}

The aim of this article was to investigate the ethical issues that relate to the use of ICT by young adults at an HEI in the Eastern Cape Province of South Africa. The study sample consisted of $102(47.2 \%)$ males and 114 (52.8\%) females. Seventy-seven per cent of the participants were aged between 17 and 21 years. This percentage is to be expected as most students enter university after school. The 22- to 30-year age group consisted of $19.4 \%$ of the study sample, while the students that were older than 30 years were the smallest group comprising $0.03 \%$. 
Slightly more students $(115,53.2 \%)$ had attended a school in the rural areas specifically, while 101 students (46.8\%) had attended a school located in an urban area. Rural schools often did not have adequate computer laboratory facilities, and this was reflected in the responses of 128 students (59.3\%) who had not received computer literacy training prior to entering the university. Almost half of the students (49.5\%) stated that they had no prior knowledge of computer ethics, but the vast majority (91.2\%) indicated that it is important to be ethical when using a computer.

The ethical behaviour of the students was grouped into three categories: piracy of software, plagiarism and cheating. The results for each of the categories are displayed in Table 1, which shows that $59.3 \%$ of the students thought it was wrong or slightly wrong to copy software for educational purposes. Interestingly, while only $65.3 \%$ of the students thought that it was wrong to download music or movies from the Internet for personal use, 91.2\% thought it was wrong to share it with friends.

The plagiarism category consisted of four questions (Table 2). The majority of the students (95.9\%) thought that it was wrong to copy and paste entire pieces of work from the Internet. The percentage of students that recognised plagiarism decreased steadily as the amount of work copied decreased. This could indicate a problem as to the definition of plagiarism among the students. When asked if two lines copied from a source without acknowledging the source was acceptable, $94.4 \%$ of the students did know that this was wrong. Seventy-four per cent of the students thought that it would be unethical to copy a paragraph and change a few words without citing the source, while only $47.2 \%$ of the students indicated that it would be wrong to

\section{TABLE 1: Software piracy category.}

\begin{tabular}{|c|c|c|c|c|c|c|c|c|}
\hline \multirow[t]{2}{*}{ Category } & \multicolumn{2}{|c|}{ Wrong } & \multicolumn{2}{|c|}{$\begin{array}{l}\text { Somewhat } \\
\text { wrong }\end{array}$} & \multicolumn{2}{|c|}{$\begin{array}{l}\text { Somewhat } \\
\text { right }\end{array}$} & \multicolumn{2}{|c|}{ Right } \\
\hline & $n$ & $\%$ & $n$ & $\%$ & $n$ & $\%$ & $n$ & $\%$ \\
\hline $\begin{array}{l}\text { Copying original software for } \\
\text { education purposes is }\end{array}$ & 111 & 51.4 & 17 & 7.9 & 33 & 15.2 & 55 & 25.5 \\
\hline $\begin{array}{l}\text { Downloading music or movies from } \\
\text { Internet is }\end{array}$ & 111 & 51.4 & 30 & 13.9 & 37 & 17.1 & 38 & 17.6 \\
\hline $\begin{array}{l}\text { Unauthorised sharing of original } \\
\text { software with friends is }\end{array}$ & 173 & 80.1 & 24 & 11.1 & 7 & 3.2 & 12 & 5.6 \\
\hline
\end{tabular}

\section{TABLE 2: Plagiarism category.}

\begin{tabular}{|c|c|c|c|c|c|c|c|c|}
\hline \multirow[t]{2}{*}{ Questions } & \multicolumn{2}{|c|}{ Wrong } & \multicolumn{4}{|c|}{$\begin{array}{l}\text { Somewhat Somewhat } \\
\text { wrong right }\end{array}$} & \multicolumn{2}{|c|}{ Right } \\
\hline & $n$ & $\overline{\%}$ & $n$ & $\%$ & $n$ & $\%$ & $n$ & $\%$ \\
\hline $\begin{array}{l}\text { Copying and pasting an essay from } \\
\text { the Internet and submitting it as } \\
\text { your own is }\end{array}$ & 195 & 90.3 & 12 & 5.6 & 2 & 0.9 & 7 & 3.2 \\
\hline $\begin{array}{l}\text { Copying two lines from a printed } \\
\text { source without acknowledging the } \\
\text { source is }\end{array}$ & 177 & 81.9 & 27 & 12.5 & 10 & 4.7 & 2 & 0.9 \\
\hline $\begin{array}{l}\text { Changing a few words of a } \\
\text { paragraph copied and pasted from } \\
\text { the Internet, so that the material } \\
\text { does not have to be cited is }\end{array}$ & 124 & 57.4 & 37 & 17.1 & 30 & 13.9 & 25 & 11.6 \\
\hline $\begin{array}{l}\text { Using a series of paragraphs that } \\
\text { have been copied and pasted from } \\
\text { a variety of Internet sites to create } \\
\text { a paper with acknowledgement to } \\
\text { the sites in your bibliography is }\end{array}$ & 81 & 37.5 & 21 & 9.7 & 22 & 10.2 & 92 & 42.6 \\
\hline
\end{tabular}

copy a series of paragraphs verbatim from different sources, even if the student acknowledged the sources in the reference list.

Table 3 provides the results for the last category: cheating. The majority of the students indicated that it may be wrong to cheat. Ninety-five per cent of the students thought that it would be wrong to lie to the lecturer about handing in an assignment when they did not, while $88.9 \%$ did not approve of buying a paper or assignment online and submitting it as their own work. Ninety-nine per cent of students thought it was wrong to chat to other students during a test, making use of their mobile phones, but only $81.2 \%$ thought it would be wrong to receive the test questions from a fellow student after they had written the test.

Only $55.0 \%$ of the students indicated that it would be ethical to use a chat room to gather information for assignment purposes, while $13.4 \%$ indicated that it may be ethical. Thirtyone percent of the students felt that it was unethical to make use of chat rooms to search for information to be used for assignment purposes.

Correlation analysis tests were conducted to determine whether relationships existed between the different factors in the literature section. The correlation coefficients provide an indication of whether the relationship is positive (changes increase or decrease in the same direction) or negative (respond in opposite directions). The results for the categories piracy, plagiarism and cheating are also discussed.

\section{Software piracy}

Although the majority of students indicated in the previous section that they knew that software piracy was wrong, the results from the t-tests showed that students' attitude towards downloading music or movies from the Internet is that it is not unethical. The results indicated a positive statistically significant difference in the ethical score between students from a rural background $(t=2.4 ; p<0.05)$, those that did not receive computer literacy training before entering university $(t=-2.97 ; p<0.05)$ and those that did not have prior knowledge of computer ethics $(t=-.97$; $p<0.05)$.

TABLE 3: Cheating category.

\begin{tabular}{|c|c|c|c|c|c|c|c|c|}
\hline \multirow[t]{2}{*}{ Questions } & \multicolumn{2}{|c|}{ Wrong } & \multicolumn{4}{|c|}{$\begin{array}{c}\text { Somewhat Somewhat } \\
\text { wrong right }\end{array}$} & \multicolumn{2}{|c|}{ Right } \\
\hline & $n$ & $\%$ & $n$ & $\%$ & $n$ & $\%$ & $n$ & $\%$ \\
\hline $\begin{array}{l}\text { Buying a paper online and } \\
\text { submitting it as your own is }\end{array}$ & 180 & 83.3 & 12 & 5.6 & 5 & 2.3 & 19 & 8.8 \\
\hline $\begin{array}{l}\text { Claiming to have attached an } \\
\text { assignment to an email when you } \\
\text { did not in order to have extra time } \\
\text { to complete the work is }\end{array}$ & 195 & 90.3 & 11 & 5.1 & 3 & 1.4 & 7 & 3.2 \\
\hline $\begin{array}{l}\text { Carrying on an instant message } \\
\text { conversation while taking a } \\
\text { computerised exam is }\end{array}$ & 200 & 92.6 & 14 & 6.5 & 2 & 0.9 & 0 & 0.0 \\
\hline $\begin{array}{l}\text { Receiving and using an email from } \\
\text { a friend about the questions on an } \\
\text { exam he and/or she just completed is }\end{array}$ & 183 & 74.7 & 14 & 6.5 & 3 & 1.4 & 16 & 7.4 \\
\hline
\end{tabular}




\section{Plagiarism}

Plagiarism was shown to be a problem among first-year students as most of the variables tested statistically significant for this category. Students from rural areas indicated that the following actions are not considered unethical:

- Buying a paper online and submitting it as your own $(t=1.98 ; p<0.05)$.

- Copying two lines from a printed source without acknowledging the source $(t=2.29 ; p<0.05)$.

- Changing a few words of a paragraph copied and pasted from the Internet $(t=2.81 ; p<0.05)$.

- Using a series of paragraphs that have been copied and pasted from a variety of Internet sites to create a paper with acknowledgement to the sites in your bibliography $(t=2.61 ; p<0.05)$.

- Writing a summary based on an online abstract of a journal article rather than reading the article itself $(t=4.2$; $p<0.05)$.

Students that did not receive any prior computer literacy training tested statistically significant for the questions 'changing a few words of a paragraph copied and pasted from the Internet' with $t=-3.44$ and $p<0.05$, and 'using a series of paragraphs that have been copied and pasted from a variety of Internet sites to create a paper with acknowledgement to the sites in your bibliography' with $t=-2.55$ and $p<0.05$. These results show that there is a negative relationship between lack of prior computer literacy training and the perceptions of the students regarding plagiarism.

Similarly, students that had no prior knowledge of computer ethics were found to be statistically significant for the question 'changing a few words of a paragraph copied and pasted from the Internet' ( $t=-2.79$ and $p<0.05)$. In addition, students also reported that 'copying two lines from a printed source without acknowledging the source' as statistically significant $(t=-2.36 ; p<0.05)$. These results show that there is a negative relationship between lack of prior knowledge about computer ethics and the perceptions of the students regarding plagiarism.

\section{Cheating}

Prior knowledge of computer ethics tested statistically significant in this category. Claiming to have attached an assignment to an email when you did not in order to have extra time to complete the work tested significant for students with no prior knowledge of computer ethics $(t=-1.96$; $p<0.05)$ as did receiving and reading an email from a friend about the questions on an exam he/she had just completed $(t=-3.34 ; p<0.05)$.

\section{Discussion}

Many Computer Science and Information Systems' lecturers in higher education have previously indicated that information ethics is an area that must be investigated and included in the curriculum in order to improve the social responsibility of young adults (Halawi \& McCarthy 2013; Jamil et al. 2013a; Straub \& Collins 1990). This statement is supported by Masrom et al. (2010), who suggested that integrating computer ethics topics into the curricula is effective in making students aware of ethical concerns in IT. This exposure to information ethics will also impact the attitude of students towards ethical behaviour when working with a computer or digital information. The results of this study showed that while students thought it was important to be ethical when using a computer, many were not aware of plagiarism issues that may arise. If these matters are addressed early on in the curriculum, the students will be able to conduct themselves in an ethically acceptable manner as the awareness around these issues will have increased.

Previous literature proposes that the background of the students will influence their perspective of information ethics (Hsieh \& Lee 2012). This was found to be true as students from rural backgrounds did not understand the ethical use of information piracy or plagiarism. This could be partly attributed to the lack of exposure to computers in rural areas. While both the national departments of Basic Education and Higher Education and Training in South Africa have adopted ICT as a means of enhancing education in the country, it is estimated that only $10 \%$ of the schools in South Africa have access to one or more computers. The reason why so few schools have computers is that the government of South Africa does not have the budget to purchase computers or provide the infrastructure necessary for ICT (Mdlongwa 2012). It is estimated that only $8.8 \%$ of schools in the Eastern Cape, the catchment area for the university in this study, has access to computers (Mdlongwa 2012). This unfortunately means that students enter higher education without the necessary computer literacy skills or exposure to topics such as information ethics.

In the previous paragraph, it was discussed how students' backgrounds influenced their perspectives on information ethics and their understanding of piracy and plagiarism. In terms of software piracy, it should be noted that young adults are the most prolific users of smart phones, which are enabled to download music and videos from the Internet (Limo 2010). Fewer students indicated that it was wrong to download these materials from the Internet for entertainment than software for other purposes, such as educational software. This can be attributed to the convenience of the Internet which makes it easy to access content and the cost of genuine software. Software piracy, therefore, has become acceptable to many of the students. Interestingly, students did not think it was acceptable to share content with their peers. Hsieh and Lee (2012) found that peer pressure can be used to reduce the rate of software piracy and to cultivate social norms. It may be possible that students do not share software as they are not sure that their peers will approve of this practice.

The issue of piracy above went hand in hand with plagiarism. Plagiarism was shown to be of concern among the cohort of students. As mentioned previously, the students from a 
rural background, in particular with no prior experience of computers or information ethics, did not understand why avoiding plagiarism was important. The amount of students that thought plagiarism was wrong decreased with the amount of text that was plagiarised. This means that firstyear students did not understand what plagiarism is or did not appreciate the consequences of plagiarism when they enter higher education. Plagiarism, and its flip side, authorship, must therefore be included in the curriculum for these students to ensure that they abide by the rules for ethical conduct, instead of assuming that the students understand the concepts.

While ICT does provide convenience to students, in that they can access information and prepare professional documents, it also provides the opportunity to be dishonest. The students with no prior knowledge of information ethics had difficulty identifying why cheating making use of ICT was wrong. Once again, if the topic of information ethics is included in the curriculum, it will raise the awareness of these issues and provide the students with a frame of reference to determine what information ethics issues are and to prevent future unethical conduct.

\section{Conclusion}

Information ethics has become an important field in recent years as computers have become an integral part of daily life. Students in higher education are most often faced with three categories of breach of information ethics: software piracy, plagiarism and cheating. While most agree that it is important for students to understand these concepts, very few HEIs have included information ethics in their curriculum. This study has shown that while students do know what software piracy is, they do not think it is wrong to copy software from the Internet, possibly because of the convenience in doing so. Universities and colleges must teach students what authorship is in order for students not to fall prey to plagiarism and unethical behaviour. Finally, the students understood that cheating making use of technology is wrong and should be avoided.

The limitation of the article is the relatively small sample size when compared with the student population at the university and self-reported data that could lead to bias. Future opportunities for research include a longitudinal study with the same cohort of students, or an action-type research where information ethics is included in the curriculum and the knowledge of students is tested before and after the intervention.

\section{Acknowledgements Competing interests}

The author declares that she has no financial or personal relationship(s) that may have inappropriately influenced her in writing this article.

\section{References}

Ajzen, I., 1991, 'The theory of planned behaviour', Organizational Behavior and Human Decision Processes 50, 179-211. http://dx.doi.org/10.1016/07495978(91)90020-T

Akbulut, Y., Sendag, S., Birinci, G., Kilicer, K., Sahin, M. \& Odabasi, H., 2008, 'Exploring the types and reasons of Internet-triggered academic dishonesty among Turkish undergraduate students', Computers \& Education 51(1), 463-473. http://dx.doi. org/10.1016/j.compedu.2007.06.003

Alshwaier, A., Youssef, A. \& Emam, A., 2012, 'A new trend for e-learning in KSA using educational clouds', Advanced Computing: An International Journal 3(1), 81-97. http://dx.doi.org/10.5121/acij.2012.3107

Bryman, A., 2012, Social research methods, Oxford University Press, Oxford.

Capurro, R., 2007, 'Information ethics for and from Africa', International Review of Information Ethics 7, 1-13.

Duarte, M., 2014, 'Formative assessment in b-learing: Effectively monitoring students learning', Second International Conference on Technological Ecosystems for Enhancing Multiculturality, TEEM'14, Salamanca, October 1-3, pp. 1-6.

Freestone, O. \& Mitchell, V., 2004, 'Generation Y attitudes towards e-ethics and internet-related misbehaviors', Journal of Business Ethics 54(2), 121-128. http://dx.doi.org/10.1007/s10551-004-1571-0

Haag, S. \& Keen, P., 1996, Information technology: Tomorrow's advantage today, McGraw Hill Companies, Inc., New York.

Halawi, L. \& McCarthy, R., 2013, 'Evaluation of ethical issues in the knowledge age: An exploratory study', Issues in Information Systems 14(1), 106-112.

Hsieh, P. \& Lee, T., 2012, 'Does age matter? Students' persepctives of unauthorized software copying under legal and ethical considerations', Asia Pacific Management Review 17(4), 361-377.

Jamil, M., Hussain, J. \& Tariq, R., 2013a, 'IT ethics: Undergraduates' perception based on their awareness', Journal of Education and Practice 4(12), 110-122.

Jamil, M., Shah, J.H. \& Tariq, R., 2013b, 'IT ethics: Undergraduates' perception based on their awareness', Journal of Education and Practice 4(12), 1-14.

Johnson, D., 1985, Computer ethics, Prentice-Hall, Englewood Cliffs, NJ.

Kim, H., Kim, J. \& Lee, W., 2013, 'IE behavior intent: A study on ICT ethics of college students in Korea', Asia-Pacific Education Researcher 23(2), 1-10.

Koch, F., Assuncao, M. \& Netto, M., 2012, A cost analysis of cloud computing for education, Springer, Berlin.

Leonard, L. \& Cronan, T., 2005, 'Attitude toward ethical behavior in computer use: A shifting model', Industrial Management \& Data Systems 105(9), 1150-1171. http://dx.doi.org/10.1108/02635570510633239

Limo, A., 2010, Information ethics and the new media: Challenges and opportunities for Kenya's education sector, viewed 05 January 2016, from http://www. africainfoethics.org/pdf/2010/presentations/Limo\%20paper.pdf

Maner, W., 1995, 'Unique ethical problems in information technology', Science and Engineering Ethics 2(2), 137-154. http://dx.doi.org/10.1007/BF02583549

Marshall, K., 1999, 'Has technology introduced new ethical problems?', Journal of Business Ethics 19(1), 81-90. http://dx.doi.org/10.1023/A:1006154023743

Mason, R., 1986, 'Four ethical issues of the information age', MIS Quarterly 10(1), 4-12. http://dx.doi.org/10.2307/248873

Masrom, M., Ismail, Z., Hussein, R. \& Mohamed, N., 2010, 'An ethical assessment of computer ethics using scenario approach', International Journal of Electronic Commerce Studies 1(1), 25-36.

Mdlongwa, T., 2012, Information and Communication Technology (ICT) as a means of enhancing education in schools in South Africa: Challenges, benefits and recommendations, Africa Institute of South Africa, Johannesburg.

Mutula, S. \& Mmakola, L., 2013, 'Information ethics integration in the curriculum at the University of KwaZulu Natal', Innovations 46, 1-18.

Oates, B., 2006, Researching information systems and computing, Sage, London.

Pierce, M. \& Henry, J., 1996, 'Computer ethics: The role of personal, informal and formal codes', Journal of Business Ethics 15(4), 425-437. http://dx.doi. org/10.1007/BF00380363

Prensky, M., 2001, 'Digital natives, digital immigrants', On the Horizon 9(5), 1-10. http://dx.doi.org/10.1108/10748120110424816

Skiba, D., 2014, 'The connected age: Mobile apps and consumer engagement', Nursing Educational Perspectives 35(3), 199-201. http://dx.doi.org/10.5480/15365026-35.3.199

Straub, D. \& Collins, R., 1990, 'Key inforamtion liability issues facing managers: Software piracy, proprietary databases, and individual rights to privacy', MIS Quarterly 14(2), 143-156. http://dx.doi.org/10.2307/248772

Sturges, P., 2009, 'Information ethics in the twenty first century', Australian and Research Libraries 40(4), 241-251. http://dx.doi.org/10.1080/00048623.2009.10721415

Teston, G., 2008, 'Software piracy among technology education students: Investigating property rights in a culture of innovation', Journal of Technology Education 20(1), 66-78. http://dx.doi.org/10.21061/jte.v20i1.a.5

Underwood, J., 2007, 'Rethinking the digital divide: Impacts on student-tutor relationships', European Journal of Education 42(2), 213-222. http://dx.doi. org/10.1111/j.1465-3435.2007.00298.x

University of North Carolina, 2014, UNC, The Writing Center, viewed 5 January 2016, from http://writingcenter.unc.edu/handouts/plagiarism/ 